Check for updates

Cite this: RSC Adv., 2019, 9, 29131

Received 12th July 2019

DOI: $10.1039 / c 9 r a 05329 h$

rsc.li/rsc-advances
Accepted 12th September 2019

\section{Hierarchical porous carbon derived from carboxylated coal-tar pitch for electrical double- layer capacitors}

\author{
Haiyang Wang, (D) ab Hongzhe Zhu, (D) ${ }^{\mathrm{b}}$ Yixuan Li, ${ }^{\mathrm{b}}$ Debang Qi, ${ }^{a}$ Shoukai Wang ${ }^{\star b}$ \\ and Kaihua Shen*a
}

Hierarchical porous carbons have been synthesized using amphiphilic carboxylated coal-tar pitch as a precursor via a simple $\mathrm{KOH}$ activation process. Amphiphilic carboxylated coal-tar pitch has a high content of hydrophilic carboxyl groups that enable it to be easily wetted in $\mathrm{KOH}$ solution and that facilitate the activation process. In the present study, the effect of the activation agent to precursor ratio on the porosity and the specific surface area was studied by nitrogen adsorption-desorption. A maximum specific surface area of $2669.1 \mathrm{~m}^{2} \mathrm{~g}^{-1}$ was achieved with a $\mathrm{KOH}$ to carboxylated pitch ratio of three and this produced a structure with micropores/mesopores. Among the various hierarchical porous carbons, the sample prepared with an activation agent to precursor ratio of two exhibited the best electrochemical performance as an electrode for an electrical double-layer capacitor in a $6 \mathrm{M} \mathrm{KOH}$ electrolyte. The specific capacitance of the sample was $286 \mathrm{~F} \mathrm{~g}^{-1}$ at a current density of $2 \mathrm{~A} \mathrm{~g}^{-1}$ and it had a capacitance-retention ratio of $93.9 \%$, even after 10000 cycles. Thus, hierarchical porous carbons derived from amphiphilic-carboxylated coal-tar pitch represent a promising electrode material for electrical double-layer capacitors.

\section{Introduction}

With the fast-growing demands for novel and high-efficiency energy-storage devices, supercapacitors (or electrochemical capacitors) have stimulated extensive interest due to their advantages of high-power capability, superior reversibility and long life cycle. ${ }^{1-3}$ On the basis of different energy storage mechanisms, supercapacitors can be divided into two types: electrical double layer capacitors (EDLCs) and pseudocapacitors. ${ }^{4}$ EDLCs utilize electrostatic adsorption of the electrolyte ions at the electrode-electrolyte interfaces, such as carbon materials, ${ }^{5,6}$ while pseudocapacitance electrode materials store the electrical energy by fast and reversible faradaic redox reactions occurring at the surface of electrodes, such as transition metal oxides ${ }^{7,8}$ and conducting polymers. ${ }^{9}$ Pseudocapacitance electrode materials possess high specific capacitance, but suffer from poor cyclability and rate capability which limit their further applications. On the contrary, porous carbon materials are the most promising candidates for commercial electrodes. An ideal electrode material is expected to have a large surface area, abundant accessible micropores for energy storage and mesopores for ion transport, interconnections between the

${ }^{a}$ State Key Laboratory of Fine Chemicals, Dalian University of Technology, Dalian, 116012, PR China. E-mail: shen_kh@dlut.edu.cn; Tel: +86-411-84986102

${ }^{b}$ Sinosteel Anshan Research Institute of Thermo-Energy Company Limited, Anshan, 114044, PR China. E-mail: wsk5840863@126.com pores for enhanced charge-storage sites and excellent charge/ discharge rates. ${ }^{\mathbf{1 0 , 1 1}}$

Fabrication of hierarchical-porous carbons (HPCs) with high surface areas and large pore volumes as electrodes have long been pursued. Nowadays, HPCs are mainly synthesized via the pyrolysis and activation of carbon precursors including fossil fuels ${ }^{12}$ biomass, ${ }^{13,14}$ synthetic polymers materials ${ }^{15-18}$ and some organic wastes. ${ }^{19}$ HPCs have been generally prepared by hard/soft templating approaches or templating/chemical activation combination methods. ${ }^{20-23}$ These strategies were successful in preparing HPCs with precise nanostructures. However, these techniques have limitations as they involve high production cost, energy consumption, longer carbonization/activation time, and more activation/template agents. ${ }^{24-26}$ Hence, it is necessary to find a rapid, efficient and economical route for the preparation of low-cost HPCs containing micropores/mesopores for supercapacitors for practical application purposes.

Coal-tar pitch (CP) contains carbonaceous polycyclicaromatic hydrocarbons as its major component and relatively high in carbon content. Therefore, it is an inexpensive and promising precursor for preparing HPCs. ${ }^{27,28}$ However, CP is composed of lamellar macromolecules in parallel stacks and has a dense structure. CP upon direct pyrolysation and carbonization, became non-porous, irregular-shaped semi-coke or coke and cannot absorb a large number of ions and thereby ineffective for energy storage. Alternatively, HPCs were also obtained by a direct $\mathrm{KOH}$-activated method of $\mathrm{CP}$, and this 
method achieved an $S_{\text {BET }}$ value of $3200 \mathrm{~m}^{2} \mathrm{~g}^{-1} \cdot{ }^{29}$ However this process had limitations (i) partial contact of CP particles upon $\mathrm{KOH}$ soaking, due to CP's irregular shapes and large sizes (ii) chemical activation from external to internal areas requires large amount of $\mathrm{KOH}$, long activation time and high temperature (iii) obtained HPCs were microporous, and not effective for energy storage at a higher charge rate.

Another approach was introduction of hydrophilic polar groups such as $\mathrm{OH}$ and $\mathrm{COOH}$ in the $\mathrm{CP}$ architecture. This methodology was promising as the lamellar structure in CP was interrupted and aggregation from $\pi-\pi$ stacking was avoided by the presence of hydrophilic groups. However, introduction of $\mathrm{OH}$ group required hazardous and strong oxidizing reagents (e.g., $\mathrm{HNO}_{3}, \mathrm{KMnO}_{4}$, and/or $\mathrm{H}_{2} \mathrm{SO}_{4}$ ) and a tedious multistep process. ${ }^{30-33}$ In addition, use of strong oxidizing agents caused extensive damage to the carbon-basal plane with a large number of chemical and topological defects on the prepared HPCs. ${ }^{34}$ The introduction of $\mathrm{COOH}$ groups in CPs were not explored yet. Hence, we report here a carboxylated coal-tar pitch (CCP) by simple Friedel-Crafts acylation followed by Baeyer-Villiger oxidation. HPCs were prepared from $\mathrm{CCP}$ by $\mathrm{KOH}$ activation and were investigated by nitrogen adsorption-desorption method, X-ray diffraction (XRD) and Raman spectroscopy. Electrochemical performances of these HPCs as an electrode for EDLCs were also evaluated.

\section{Experimental procedures}

\subsection{Preparation of CCP}

CCP was prepared by the Friedel-Crafts acylation followed by Baeyer-Villiger oxidation (Scheme 1). Under an argon atmosphere, $50 \mathrm{~g}$ of CP was dissolved in $500 \mathrm{~mL}$ of dichloroethane. Next, $50 \mathrm{~g}$ of $\mathrm{AlCl}_{3}$ and $30 \mathrm{~g}$ of oxalyl chloride were added dropwise. The reaction system was heated to $40{ }^{\circ} \mathrm{C}$ for $6 \mathrm{~h}$. After the reaction, the mixture was quenched by $100 \mathrm{~mL}$ of ethanol. Subsequently, the reaction mixture was filtered and washed with ethanol and hydrochloric acid. The filter cake was washed with distilled water at least three times. The diketone functional coal-tar pitch (DKCP) was dried to a constant weight in vacuum under $80{ }^{\circ} \mathrm{C}$. The weight yield of DKCP (based on CP) was $112 \%(\mathrm{wt} \%)$.

The $15 \mathrm{~g}$ DKCP sample was dispersed into $75 \mathrm{~mL}$ of ethanol, and then $75 \mathrm{~mL}$ of $30 \%$ hydrogen peroxide solution was added dropwise. The mixture was then kept at $30^{\circ} \mathrm{C}$ and stirred for $6 \mathrm{~h}$ in a water bath. After the reaction, the mixture was filtered and washed with distilled water at least three times. The final sediment, i.e., the carboxylated coal-tar pitch (CCP), was dried to a constant weight in vacuum under $80{ }^{\circ} \mathrm{C}$. The weight yield of CCP (based on DKCP) was 96\% (wt\%).

\subsection{Carbonization/activation}

Aqueous $30 \% \mathrm{KOH}$ was used for the activation of CCP. The mass ratio of $\mathrm{KOH}$ to $\mathrm{CCP}$ varied from 1 to 3 . CCP was added to the aqueous $30 \% \mathrm{KOH}$ solution and stirred for $1 \mathrm{~h}$ and then dried to a constant weight in vacuum under $80{ }^{\circ} \mathrm{C}$ for $12 \mathrm{~h}$. The dried materials were carbonized and activated in a tube furnace at
$800{ }^{\circ} \mathrm{C}$ for $2 \mathrm{~h}$ under a flow of nitrogen. After activation, the samples were washed three times with $1 \mathrm{M} \mathrm{HCl}$ solution and rinsed with deionized water 3 to 5 times until a pH of 7 was attained for the washing solution. Finally, the samples were dried at $120^{\circ} \mathrm{C}$ for $12 \mathrm{~h}$ and were referred as HPC- $x$, where $x=1$, $2,3, x$ represents the weight ratio of $\mathrm{KOH}$ to $\mathrm{CCP}$.

\subsection{Measurements and analyses}

Fourier transform infrared spectroscopy (FTIR) was performed on a Thermo Nicolet-360 spectrometer (USA). Elemental analysis (EA) (carbon, hydrogen, oxygen and nitrogen) was done with a Vario Macro EL analyzer (Germany). Thermogravimetric analysis (TGA) was performed using a HCT-1 instrument (China). Surface morphology of HPCs were analyzed by a JSM-6700F field emission scanningelectron microscope (FESEM, Japan). Powder X-ray diffraction (XRD) spectra and Raman spectra were recorded on a D8 ADVANCE A25 X-ray powder diffractometer (Germany) using $\mathrm{Cu}-\mathrm{K} \alpha$ radiation $(\lambda=1.541 \AA)$ and a 769G05 laser Raman spectrometer (UK), respectively. Surface chemical composition was determined by X-ray photoelectron spectroscopy (XPS) on a Thermo ESCALAB250, USA. The surface area and porosity of HPCs were estimated from the isotherms of nitrogen adsorption-desorption at $77 \mathrm{~K}$ by Accelerated Surface Area \& Porosimetry (ASAP2020). The specific surface area was calculated by Brunauer-Emmett-Teller (BET) equation. The pore-size (diameter) distributions (PSDs) were determined using the nonlocal-density functional theory, assuming slit-pores geometry.

\subsection{Electrochemical measurements}

The carbon electrode was fabricated as follows. HPCs and polytetrafluoroethylene (PTFE) were mixed in a weight ratio of $9: 1$. The resulting mixture was rolled into a thin film and further cut into a circular shape (12 $\mathrm{mm}$ diameter). Each round film had a mass loading of $2.5 \mathrm{mg} \mathrm{cm} \mathrm{cm}^{-2}$. The film was dried under vacuum at $120{ }^{\circ} \mathrm{C}$ for $2 \mathrm{~h}$. This was then pressed onto nickel foams to fabricate supercapacitor electrodes. Finally, the electrodes were soaked in a $6 \mathrm{M} \mathrm{KOH}$ solution degassed using a vacuum for $2 \mathrm{~h}$. Cyclic voltammetry (CV) and electrochemical-impedance spectroscopy (EIS) were conducted on a CHI760E electrochemical workstation (Chenhua, Shanghai, China). EIS was carried out over a frequency range of $100 \mathrm{KHz}$ to $0.01 \mathrm{~Hz}$ with an amplitude of $5 \mathrm{mV}$. The galvanostatic charge-discharge (GCD) measurements and life-cycle tests were conducted on a supercapacitance test system (SCT) by Arbin Instruments, USA. The specific capacitance of the working electrodes was calculated from the galvanostatic-discharge process via the following equations:

$$
C_{\mathrm{s}}=\frac{I \times \Delta t}{m \times \Delta V}
$$

where $C_{\mathrm{s}}\left(\mathrm{F} \mathrm{g}^{-1}\right)$ is the specific capacitance of the three-electrode system, $I$ is the discharge current (A), $\Delta t(\mathrm{~s})$ is the discharge time, $\Delta V(\mathrm{~V})$ is the voltage change excluding the voltage drop during the discharge process, and $m(\mathrm{~g})$ is the mass of the of the active material. 


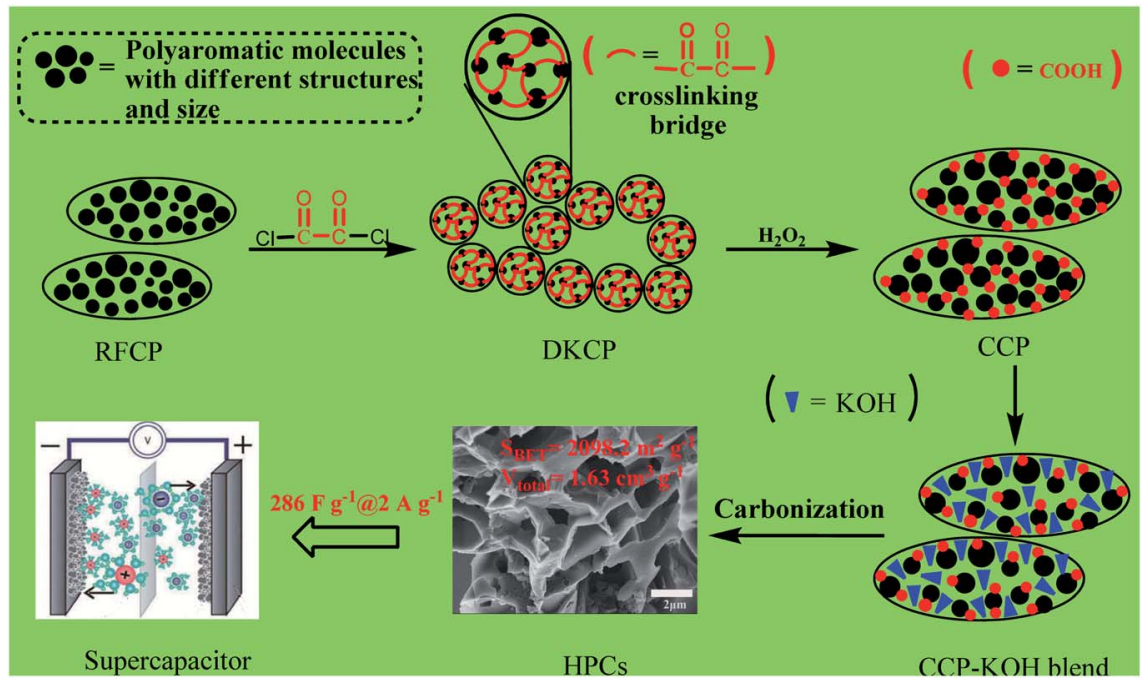

Scheme 1 Preparation of super capacitor from coal tar via carboxylated coal-tar pitch (CCP) followed by carbonization.

Table 1 The bulk and surface elemental compositions of CP and CCP

\begin{tabular}{|c|c|c|c|c|c|c|c|c|}
\hline \multirow[b]{2}{*}{ Sample } & \multicolumn{6}{|c|}{ Element analysis (wt\%) } & \multicolumn{2}{|l|}{ XPS } \\
\hline & $\mathrm{C}$ & $\mathrm{H}$ & $\mathrm{O}$ & $\mathrm{N}$ & $\mathrm{C} / \mathrm{H}$ & $\mathrm{C} / \mathrm{O}$ & C/at\% & $\mathrm{O} / \mathrm{at} \%$ \\
\hline $\mathrm{CP}$ & 93.2 & 4.7 & 1.9 & 0.2 & 1.65 & 65.40 & 95.2 & 4.6 \\
\hline CCP & 78.8 & 2.6 & 18.4 & 0.2 & 2.53 & 5.71 & 83.6 & 15.3 \\
\hline
\end{tabular}

In a two-electrode cell, the two symmetrical electrodes and a porous polypropylene separator were sandwiched together in a poly(tetrafluoroethylene) cell. The specific capacitance of the single electrode was calculated as: ${ }^{35,36}$

$$
C_{\mathrm{s}}=\frac{4 \times I \times \Delta t}{m \times \Delta V}
$$

where $I(\mathrm{~A}), \Delta t(\mathrm{~s}), m(\mathrm{~g}), \Delta V(\mathrm{~V})$ are the current, the discharge time, the total mass of active material in both electrodes, and
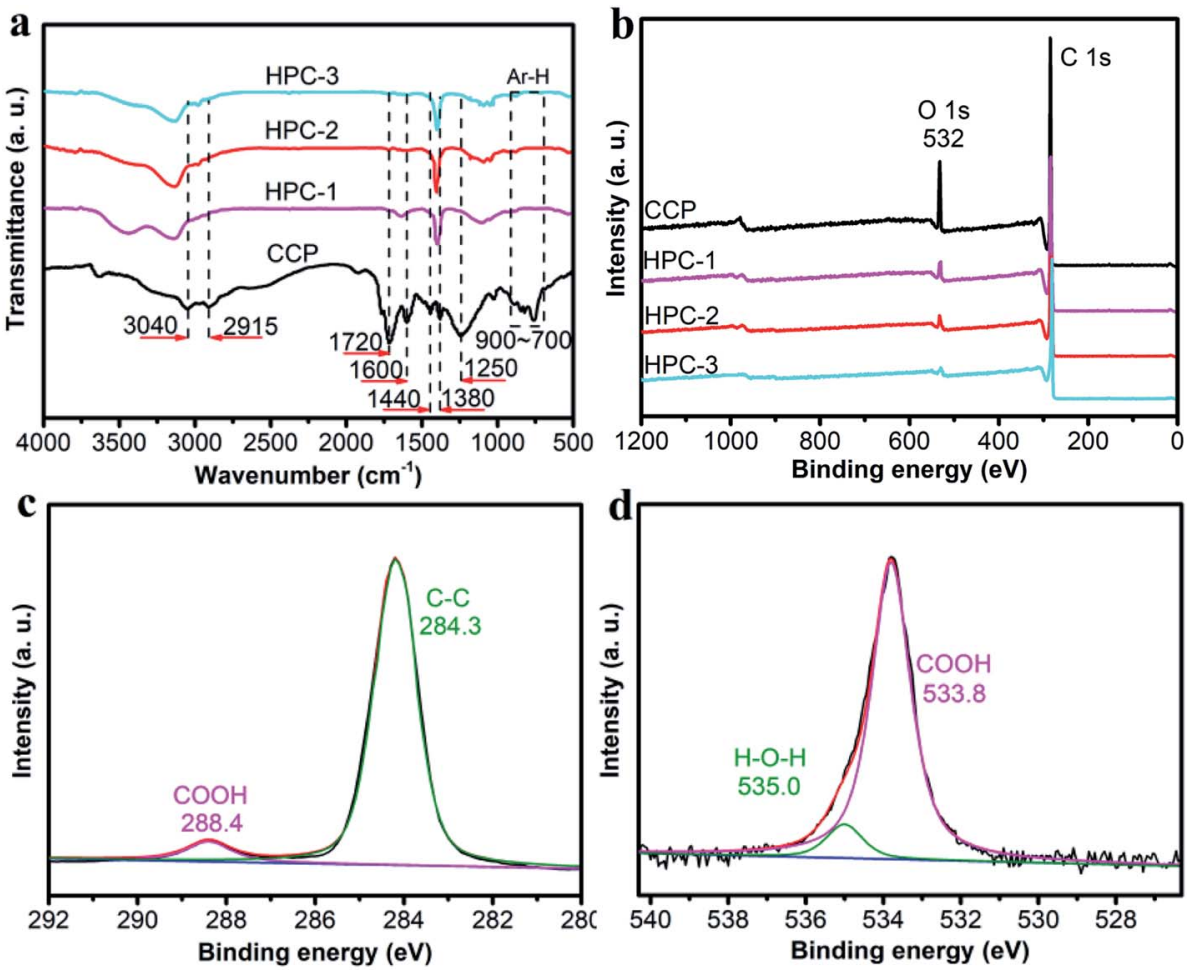

Fig. 1 (a) FTIR spectra; (b) XPS wide-scan spectra of CCP, HPC-1. HPC-2, HPC-3; (c) XPS spectra of CCP C 1s; (d) XPS spectra of CCP O 1s. 

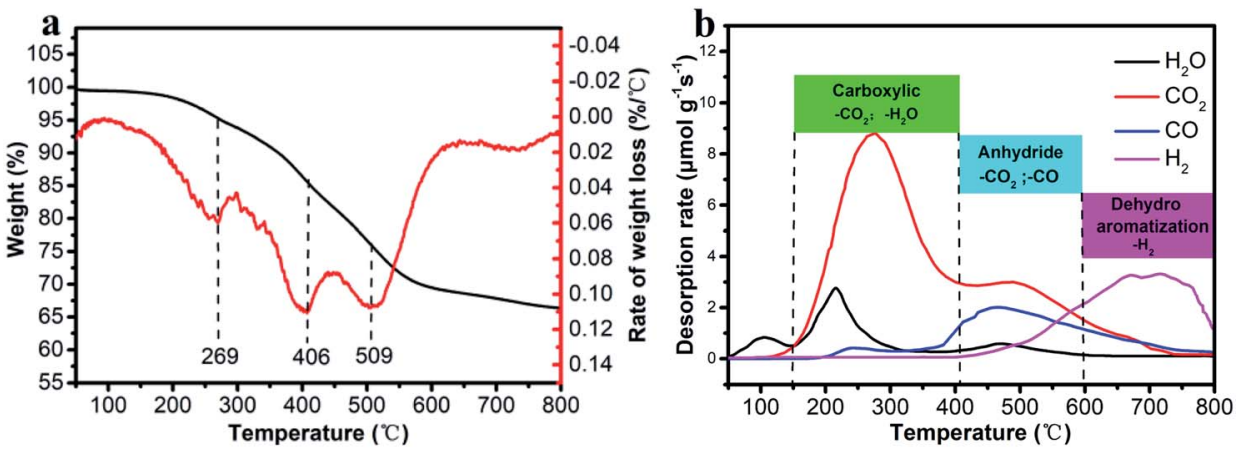

Fig. 2 TGA (a) and TPD profiles (b) of CCP.

the voltage change excluding the IR drop during the discharge process, respectively.

The energy and power density of the symmetric supercapacitor system were calculated by the following eqn (3) and (4):

$$
\begin{gathered}
E_{\mathrm{t}}=\frac{C_{\mathrm{s}} \times \Delta V^{2} \times 1000}{2 \times 4 \times 3600} \\
P_{\mathrm{t}}=\frac{E_{\mathrm{t}} \times 3600}{\Delta t}
\end{gathered}
$$

where $E_{\mathrm{t}}\left(\mathrm{W} \mathrm{h} \mathrm{kg}^{-1}\right)$ is the specific energy density, $P_{\mathrm{t}}\left(\mathrm{W} \mathrm{kg}^{-1}\right)$ is the specific power density, $C_{\mathrm{s}}\left(\mathrm{F} \mathrm{g}^{-1}\right)$ is the single electrode specific capacitance of the symmetric system, $\Delta V(\mathrm{~V})$ is the voltage change excluding the IR drop during the discharge process, and $\Delta t$ is the discharge time.

\section{Results and discussion}

\subsection{Material characterization}

Table 1 represents the bulk and surface elemental compositions of CP and CCP. EA data for CCP showed an oxygen content of $18.4 \%$ with $\mathrm{C} / \mathrm{O}$ ratio of 5.71 , representing an average of one carboxylic-acid group for 11.42 carbons. Fig. 1a represents the FTIR spectra of CCP and HPCs. For CCP, the signals at 3040 and $2915 \mathrm{~cm}^{-1}$ result from aromatic C-H stretching vibrations and aliphatic C-H stretching vibrations, respectively. ${ }^{37}$ The signals at approximately $1720 \mathrm{~cm}^{-1}$ are assigned to carboxylic acid $\mathrm{C}=\mathrm{O}$ stretching vibrations and the signals at $1600 \mathrm{~cm}^{-1}$ are attributed to aromatic $\mathrm{C}=\mathrm{C}$ stretching vibrations. ${ }^{38}$ The peaks at $1440 \mathrm{~cm}^{-1}$ and $1380 \mathrm{~cm}^{-1}$ are attributed to the $\mathrm{C}-\mathrm{H}$ bending vibration of methyl and methylene. ${ }^{39}$ For the HPCs, the significant decrease in the intensity of signals corresponding to the $\mathrm{C}=\mathrm{O}$ group confirmed the loss of $\mathrm{COOH}$ groups during the KOH-activation process. The introduction of carboxyl groups induces cross-linking of the $\mathrm{CP}$ structure, which prevents the melting and orderly rearrangement of the CP during the hightemperature carbonization process, and inhibits the graphitization process. The evolution of gas $\left(\mathrm{CO}_{2}\right.$ and $\left.\mathrm{CO}\right)$ during the high-temperature process changes the microstructure of the carbon materials and plays a dual regulation role.

XPS wide-scan spectra of CCP and HPC samples are represented in Fig. 1b. The intensity of oxygen $\mathrm{O} 1 \mathrm{~s}$ peak located at $532 \mathrm{eV}$ was significantly stronger in CCP indicating a high concentration of oxygen-containing groups in CCP than in HPC. In the $\mathrm{C}$ 1s spectrum of the CCP (Fig. 1c), there were two peaks representing different types of functional groups, namely $\mathrm{C}-\mathrm{C}$, $\mathrm{C}=\mathrm{C}$, and $\mathrm{C}-\mathrm{H}$ bonds $(284.3 \mathrm{eV})$, and $\mathrm{O}=\mathrm{C}-\mathrm{O}$ bonds $(288.4$ eV). ${ }^{40}$ The O 1s spectrum of the CCP (Fig. 1d) showed a peak at $533.8 \mathrm{eV}$ and can be assigned to $\mathrm{O}=\mathrm{C}-\mathrm{O}$ bonds. The minor peak at $535.0 \mathrm{eV}$ can be attributed to the physically absorbed moisture on samples. These observations are consistent with FT-IR spectroscopy and elemental analysis indicating the presence of $\mathrm{COOH}$ groups in CCP and their absence in HPCs.

The thermal behavior CCP was obtained from their TGA (Fig. 2a) and TPD profiles (Fig. 2b). From room temperature to $200{ }^{\circ} \mathrm{C}$, there was minimal weight loss $(1.6 \%)$, which can be assigned to the removal of the adsorbed water. The mass loss between $200{ }^{\circ} \mathrm{C}$ and $600{ }^{\circ} \mathrm{C}$ was significant $(29.9 \%)$ and can be assigned to the crosslinking and decomposition reaction of

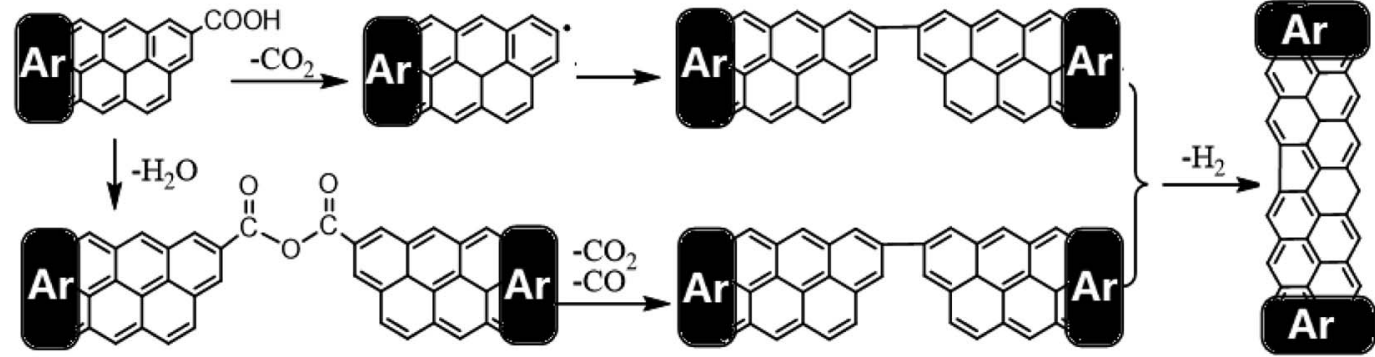

Fig. 3 Thermal decomposition pathways of CCP leading to HPC formation. 

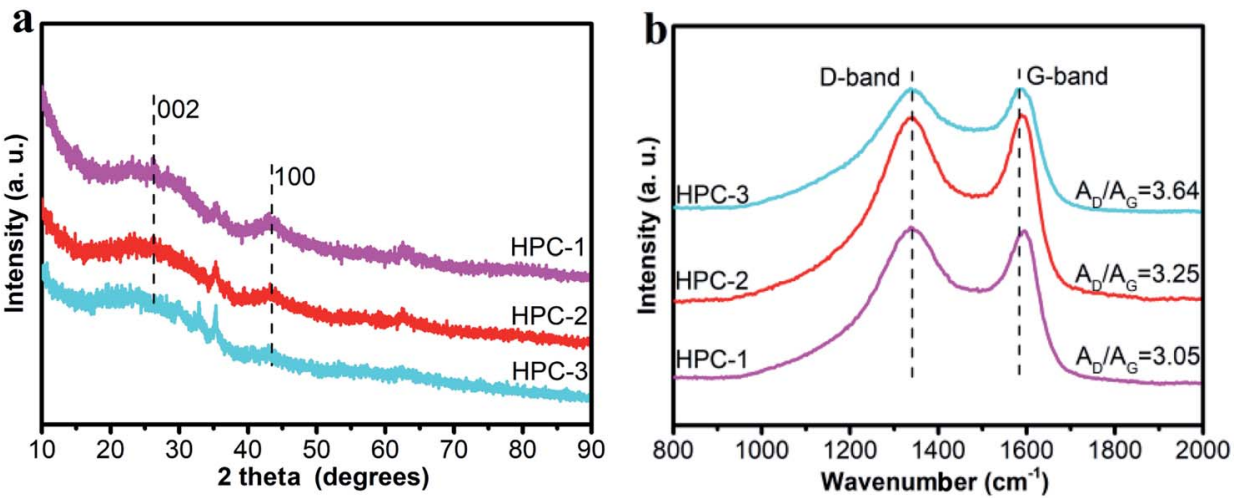

Fig. 4 XRD (a) and Raman spectra; (b) of HPC-1, HPC-2 and HPC-3.

$\mathrm{COOH}$ groups and carboxylates. ${ }^{41}$ The mass loss between $600{ }^{\circ} \mathrm{C}$ and $800{ }^{\circ} \mathrm{C}$ was $3 \mathrm{wt} \%$ and can be attributed to the dehydroaromatization. The TPD profile of $\mathrm{CO}_{2}$ shows the highest peak at $262{ }^{\circ} \mathrm{C}$ with a strong shoulder at $402{ }^{\circ} \mathrm{C}$ and a large tail indicating the presence of different $\mathrm{CO}_{2}$ releasing groups such as anhydrides.

Based on the TGA and TPD results, the two possible pathways for the thermal decomposition of ArCOOH are (1) decarboxylation via a free-radical process to produce aryl radicals, which in turn being highly reactive extract hydrogen or combine themselves to form polyaromatic structures; ${ }^{42}$ (2) dehydration reaction leading to the formation of anhydride-crosslinked bridges between the adjacent aromatic rings and subsequent pyrolysis, forming polyaromatic structures. ${ }^{43}$ Formation of anhydrides can be reasoned to the dehydration of two neighboring carboxylic groups, and subsequent disintegration to generate $\mathrm{CO}$ and $\mathrm{CO}_{2},{ }^{44}$ the decomposed route of $-\mathrm{COOH}$, as observed in Fig. 3.

\subsection{Surface morphology characterization of HPCs}

The XRD (a) and Raman spectra (b) of HPCs are presented in Fig. 4 . The broad peaks at approximately $25^{\circ}$ and $43^{\circ}$ in XRD spectra are indicative of amorphous characteristic of HPCs. ${ }^{45}$ The amorphous property of HPCs was also analyzed by Raman spectra, as shown in Fig. 4b. The D band at approximately $1352 \mathrm{~cm}^{-1}$ represents the defective graphitic structures and disordered carbons, while the $\mathrm{G}$ band at approximately $1585 \mathrm{~cm}^{-1}$ refers to the bond stretching of $\mathrm{sp}^{2}$-hybridized carbons. ${ }^{46}$ The integration-area ratio for $\mathrm{D}$ and $\mathrm{G}$ bands $\left(A_{\mathrm{D}} / A_{\mathrm{G}}\right)$ is 3.05, 3.25 and 3.64 for HPC-1, HPC-2 and HPC-3, respectively, indicating the low graphitization degree in all HPCs. ${ }^{47}$ Moreover, the $A_{\mathrm{D}} / A_{\mathrm{G}}$ ratio of HPC-3 is the highest among the three samples because the highest activation degree of $\mathrm{KOH}$ results in the maximum lattice defects in HPC-3. Together with XRD results, these results indicate that the structure of the obtained carbon materials can be tuned by changing the dosage of $\mathrm{KOH}$.

The morphology of HPCs was investigated by the FESEM technique and the results are represented in Fig. 5. The usage of
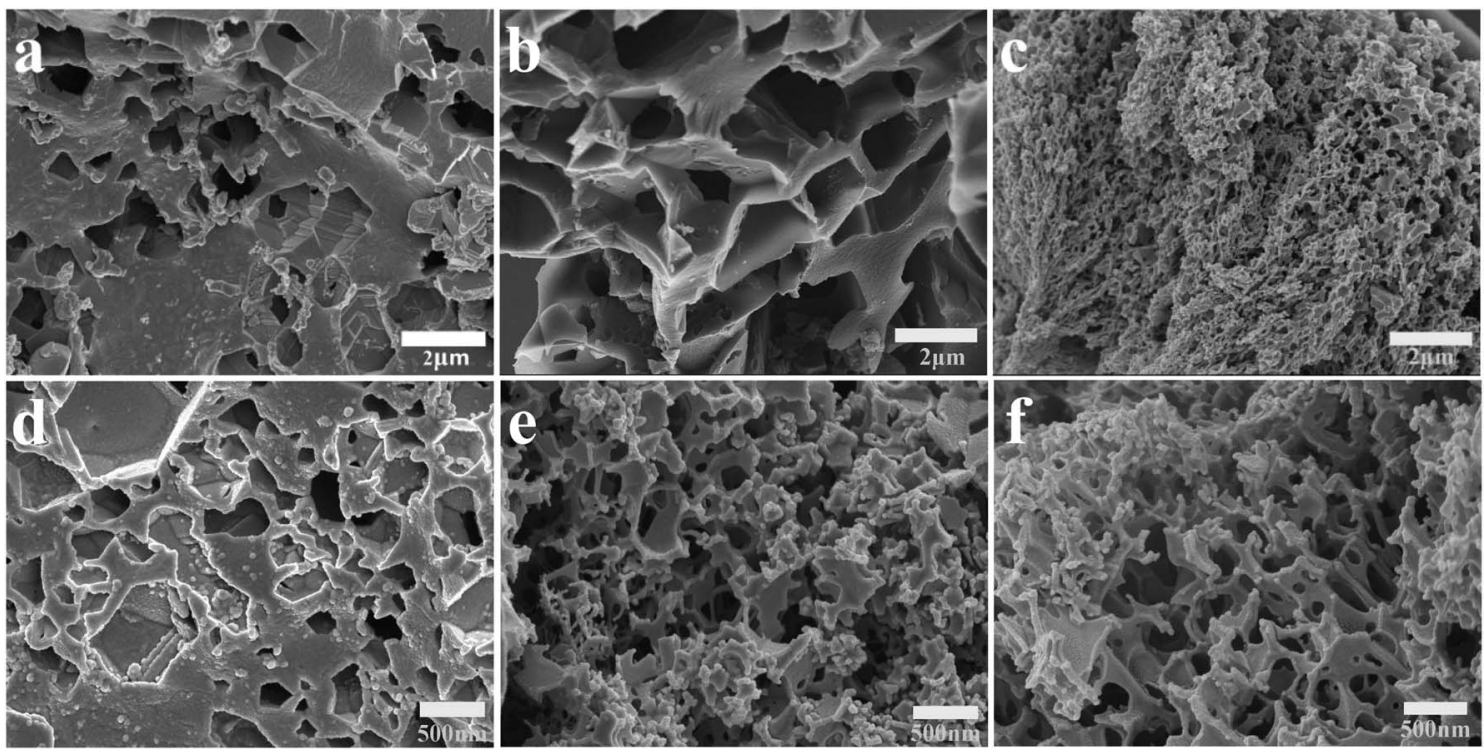

Fig. 5 SEM images of HPC-1 (2 $\mu \mathrm{m}$ (a), $500 \mathrm{~nm}(\mathrm{~d})), \mathrm{HPC}-2(2 \mu \mathrm{m}$ (b), $500 \mathrm{~nm}(\mathrm{e}))$, and HPC-3 (2 $\mu \mathrm{m}$ (c), $500 \mathrm{~nm}$ (f)). 

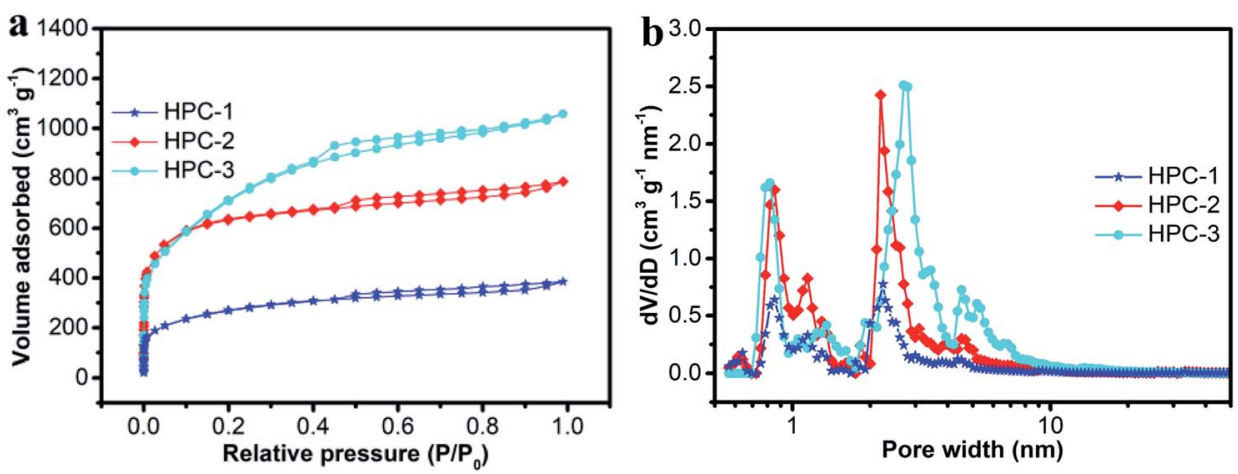

Fig. $6 \mathrm{~N}_{2}$ adsorption/desorption isotherms (a) and pore-size distribution; (b) for HPC-1, HPC-2 and HPC-3.

the $\mathrm{KOH}$ was the main governing index that affected their porous nanostructure. The FESEM images indicate that HPC-2 possessed a homogeneous sheet-like structure and that the carbon sheets were interconnected (Fig. 5b and e). For HPC-1, the pore structure is undeveloped due to the small amount of activator (Fig. 5a and d). However, HPC-3, upon increasing the usage of $\mathrm{KOH}$, has many coralloid micro-mesopores, and the carbon pores were interconnected (Fig. $5 \mathrm{c}$ and f). Therefore, the morphology and the pore sizes of the HPCs were tuned by the dosage of $\mathrm{KOH}$ usage.

The $\mathrm{N}_{2}$ adsorption-desorption isotherm (Fig. 6a) and poresize distribution of the HPCs (Fig. 6b) were also determined. The isotherms exhibited typical characteristics of type I/IV, with a sharp adsorption capacity at low relative pressures, a knee at $P / P_{0}$ in the range of $0.05-0.4$ and a platform without obvious hysteresis loops in the high $P / P_{0}$ pressure region, indicating abundant micropores and narrow mesopores in the HPCs. ${ }^{48}$ Fig. $6 \mathrm{~b}$ is the pore diameter distributions of HPCs. The mesopore diameter of HPC- 1 and HPC-2 mainly ranges from 2.0 to $4.0 \mathrm{~nm}$, while that of HPC-3 ranges from 2.0 to $8.0 \mathrm{~nm}$. For HPC3 , the enlarged mesopores are ascribed to extra activation of increased $\mathrm{KOH}$ dosage to some small mesopores $(2.0-4.0 \mathrm{~nm})$. Thus, the surface functional groups of the $\mathrm{CP}$ and the usage of $\mathrm{KOH}$ provide a meaningful contribution to pore structure.

The pore-structure data of HPCs are listed in Table 2. The $S_{\mathrm{BET}}$ and $V_{\text {total }}$ of HPCs increased in the order of HPC-1 (1095.1 $\left.\mathrm{m}^{2} \mathrm{~g}^{-1}, 1.05 \mathrm{~cm}^{3} \mathrm{~g}^{-1}\right)<$ HPC-2 $\left(2098.2 \mathrm{~m}^{2} \mathrm{~g}^{-1}, 1.63 \mathrm{~cm}^{3} \mathrm{~g}^{-1}\right)<$ HPC-3 $\left(2669 \mathrm{~m}^{2} \mathrm{~g}^{-1}, 1.98 \mathrm{~cm}^{3} \mathrm{~g}^{-1}\right)$. The high surface areas observed in HPCs can be due to the presence of $\mathrm{COOH}$ groups in CCP making CCP readily soluble in $\mathrm{KOH}$ solution favoring homogeneous activation. ${ }^{49}$ Based on the above analysis, we conclude that the pore structure of HPCs can be tuned by changing the dosage of $\mathrm{KOH}$.
In EDLCs, pore size plays an important role in addition to surface area as specific capacitance is governed by the easy accessibility of electrolyte to the pores of electrodes. Micropores can create bottlenecks and prevent solvated ions from entering into interior surfaces of the pores. According to Raymundo-Piñero et al.,$^{50}$ the optimal pore size for an effective double-layer formation in an aqueous electrolyte media is approximately $0.7 \mathrm{~nm}$. It is clear from Fig. $6 \mathrm{~b}$ that all of the HPCs exhibited hierarchical porous structures. The ultrafine micropores had pore-width peaks of 0.8 and $0.9 \mathrm{~nm}$ and the micropores had a maximum pore width of $1.2 \mathrm{~nm}$ providing a highly ion-accessible surface, which is crucial for the formation of EDLCs. ${ }^{51}$ The mesopores were in the range of 2$8 \mathrm{~nm}$, exhibiting fast ion transport and low resistance for charge transfer.

\subsection{Electrochemical characterization}

The electrochemical performances of HPCs were investigated by $\mathrm{CV}$ with a three electrode system in a $6.0 \mathrm{M} \mathrm{KOH}$ solution at a scan rate of $50 \mathrm{mV} \mathrm{s}^{-1}$ (Fig. 7a). The CV curves of all HPC electrodes exhibited a typical rectangular $I-V$ curve without any redox peaks between -1.0 to $0 \mathrm{~V}$, suggesting that all HPCs show a pure capacitive behavior. ${ }^{52}$ The rectangular curves at a high scanning rate indicated better electrochemical stability and rate capability due to the fast ion transport occurring in the pores of the electrode. The galvanostatic charge-discharge curve for the HPC electrodes at a current density of $1 \mathrm{~A} \mathrm{~g}^{-1}$ are shown in Fig. 7b. All curves were nearly triangular in shape, which is typical behavior for capacitive electrodes $.^{53} \mathrm{HPC}-1$ had a smaller specific capacitance than HPC-2 and HPC-3. When the KOH to CCP ratio was increased from 1 to 2 in HPC- 2 the gravimetricspecific capacitance increased rapidly from 230 to $320 \mathrm{~F} \mathrm{~g}^{-1}$. When the ratio was further increased from 2 to 3 , there was no

Table 2 Pore-structure data of HPCs

\begin{tabular}{llclll}
\hline Samples & $S_{\text {BET }}\left(\mathrm{m}^{2} \mathrm{~g}^{-1}\right)$ & $S_{\text {meso }}\left(\mathrm{m}^{2} \mathrm{~g}^{-1}\right)$ & $V_{\text {total }}\left(\mathrm{cm}^{3} \mathrm{~g}^{-1}\right)$ & $V_{\text {micro }}\left(\mathrm{cm}^{3} \mathrm{~g}^{-1}\right)$ & 0.39 \\
\hline HPC-1 & 1095.1 & 211.2 & 1.05 & 0.31 & 0.66 \\
HPC-2 & 2098.2 & 884.3 & 1.63 & 0.29 & 1.32 \\
HPC-3 & 2669.1 & 1582.1 & 1.98 & $V_{\text {meso }}\left(\mathrm{cm}^{3} \mathrm{~g}^{-1}\right)$ \\
& & & &
\end{tabular}



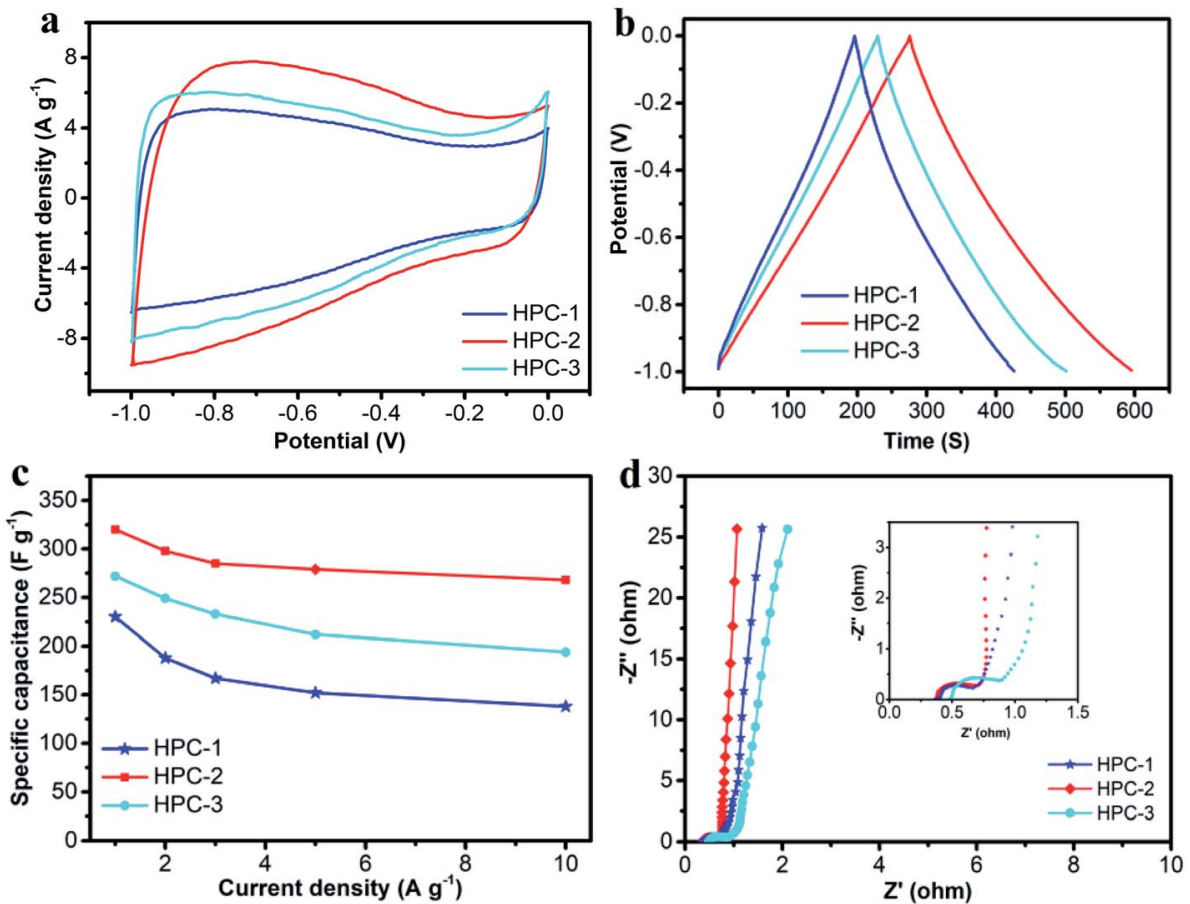

Fig. 7 Electrochemical performance of HPC electrodes via a three-electrode system in a $6.0 \mathrm{M}$ aqueous solution of $\mathrm{KOH}$ (a) $\mathrm{CV}$ curves at $50 \mathrm{mV}$ $\mathrm{s}^{-1}$. (b) Charge-discharge profiles at $1 \mathrm{~A} \mathrm{~g}^{-1}$. (c) Capacitance at different current densities. (d) Nyquist plots of electrodes from HPCs with insets, in the frequency range $100 \mathrm{kHz}$ to $0.01 \mathrm{~Hz}$ with an ac perturbation of $5 \mathrm{mV}$.

further increase in the capacitance. This can be ascribed to the low surface area and ultrafine micropores in HPC-1, which are not favorable for fast diffusion of the electrolyte into the pores.
Micropores limited the motion of the ions thus, lending the inner parts of the electrode inaccessible at high charge/ discharge rates.
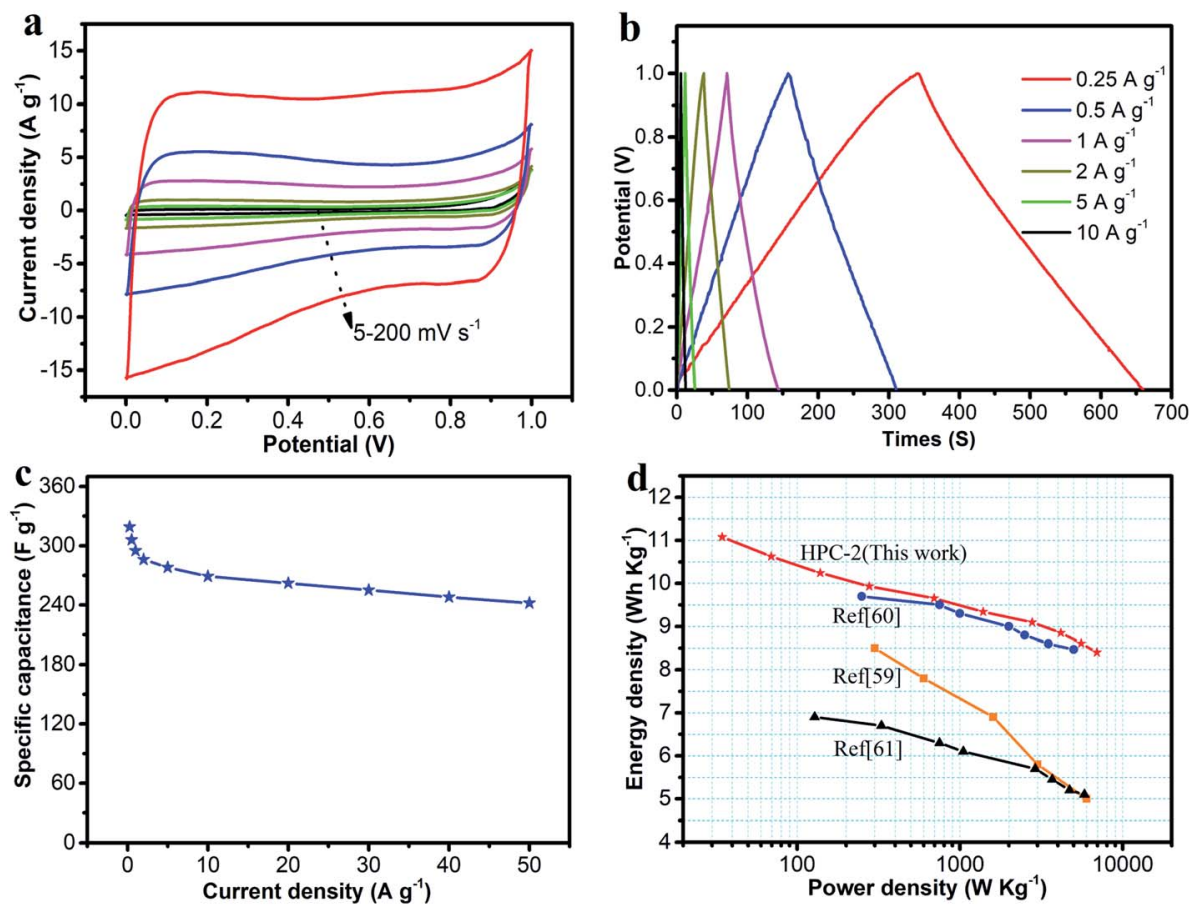

Fig. 8 Capacitive performances of symmetric electrodes for HPC-2 in $6.0 \mathrm{M}$ aqueous solution of KOH: (a) CV curves at scanning rates of 5$200 \mathrm{mV} \mathrm{s}^{-1}$; (b) charge-discharge profiles at current densities of $0.25-10 \mathrm{~A} \mathrm{~g}^{-1}$; (c) plot of specific capacitance vs. current density; (d) Ragone plot of energy density vs. power density. 

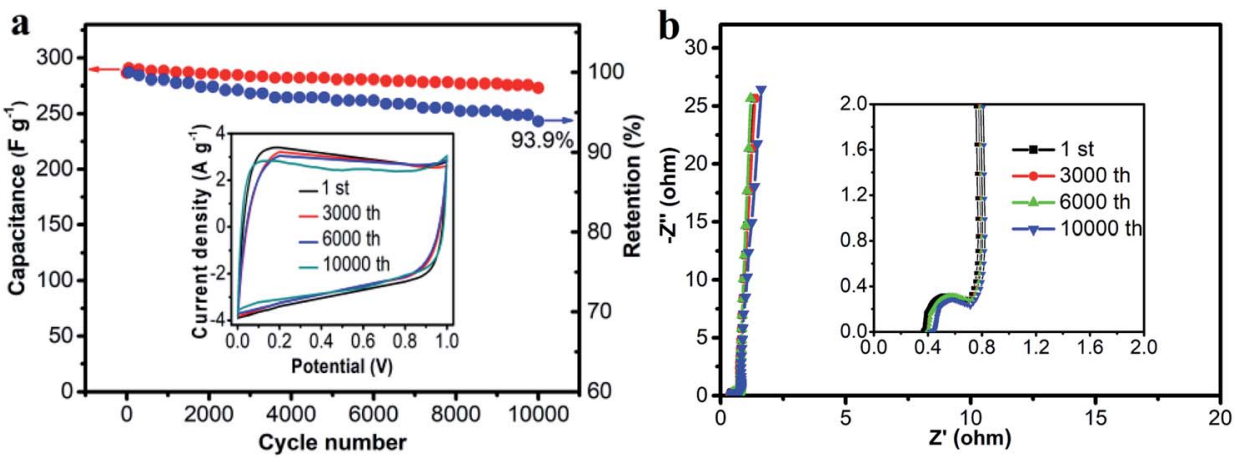

Fig. 9 (a) Plot of specific capacitance (HPC-2 electrode) vs. the number of cycles Inset: CV curves at different cycles. (b) Nyquist plots of the different cycles with insets representing the high frequency region.

Fig. $7 \mathrm{c}$ represent the relationship between specific capacitance and current density from which performance rate of all HPCs were determined. The general trend in all HPCs is that the specific capacitance decreases with the increasing current density. ${ }^{54}$ At a current density of $1 \mathrm{~A} \mathrm{~g}^{-1}$ HPC-2 exhibited a capacitance of $320 \mathrm{~F} \mathrm{~g}^{-1}$ which is higher than that of HPC-1 $\left(230 \mathrm{~F} \mathrm{~g}^{-1}\right)$ and HPC-3 $\left(272 \mathrm{~F} \mathrm{~g}^{-1}\right)$. BET surface area and $V_{\text {total }}$ of HPC-2 $\left(2098.2 \mathrm{~m}^{2} \mathrm{~g}^{-1}, 1.63 \mathrm{~cm}^{3} \mathrm{~g}^{-1}\right)$ are both smaller than HPC-3 $\left(2669 \mathrm{~m}^{2} \mathrm{~g}^{-1}, 1.98 \mathrm{~cm}^{3} \mathrm{~g}^{-1}\right)$, however, the EDLC of HPC-3 $\left(272 \mathrm{~F} \mathrm{~g}^{-1}\right.$ at $\left.1 \mathrm{~A} \mathrm{~g}^{-1}\right)$ is lower than HPC-2 $\left(320 \mathrm{~F} \mathrm{~g}^{-1}\right.$ at $\left.1 \mathrm{~A} \mathrm{~g}^{-1}\right)$. Again, the same trend was followed during the increase in current density. At a high current density of $10 \mathrm{~A} \mathrm{~g}^{-1}$, HPC-2 exhibited a specific capacitance of $268 \mathrm{~F} \mathrm{~g}^{-1}$, and retained about $83.8 \%$ of the specific capacitance. The capacitance retentions in the same current range were $60.0 \%$ and $71.3 \%$ for HPC-1 and HPC-3, respectively. This result is in good agreement with the results of charge-discharge curves of the HPC electrodes in Fig. $7 \mathrm{~b}$.

To further evaluate the electrochemical performances of HPC supercapacitors, the EIS was obtained at a frequency ranging from $100 \mathrm{kHz}$ to $0.01 \mathrm{~Hz}$. Fig. 7d presents the Nyquist plots of HPCs. It can be found that all the HPC supercapacitors present a straight line parallel to the $Y$ axis at the low-frequency part, which is indicative of an ideal capacitive behavior..$^{55}$

Size of semicircle in high to medium frequency regime which symbolizes charge transfer resistance $\left(R_{\mathrm{ct}}\right)$. Nyquist plots revealed that electrodes from all HPCs have similar impedance behaviors. In the high-frequency region, the intercept of the semicircle with the real axis corresponds to the internal resistance. This is similar for all HPCs, suggesting that they have a steady conductivity. The HPC-2 electrode has a smaller semicircle in the high-frequency region compared with HPC-1 and HPC-3 (Fig. 7d, inset), indicating that it possesses excellent electrical conductivity and the fastest charge transfer speed among the three samples. This is because in HPC- 2 there are abundant mesopores, facilitating the electrolytes to shuttle back and forth in comparison with HPC-1 and HPC-3, thus leading to a facile adsorption/desorption process at the electrolyte-carbon interface, and hence a smaller semicircle is observed.
Since the three-electrode configuration described above might produce errors leading to overestimating of capacitance, symmetric supercapacitor was assembled using HPC-2, both as the positive- and negative-electrodes. Fig. 8a shows the CV curves at scanning rates of $5-200 \mathrm{mV} \mathrm{s}^{-1}$ in a $6.0 \mathrm{M} \mathrm{KOH}$ solution. All the CV curves were in a perfect rectangular shape without any redox peaks or distortions suggesting faster ion/ charge transport within electrodes and a near-ideal capacitive behavior with an excellent rate capability. Fig. 8b shows the galvanostatic charge-discharge curves of the HPC-2-based supercapacitor at current densities from $0.25-10 \mathrm{~A} \mathrm{~g}^{-1}$. The symmetric linear charge and discharge curves with negligible voltage drop demonstrated a high coulombic efficiency and a minimal internal resistance. The specific capacitances at different current densities are shown in Fig. 8c. From the discharge curve, the specific capacitance at a constant current density of $0.25 \mathrm{~A} \mathrm{~g}^{-1}$ was found to be $319 \mathrm{~F} \mathrm{~g}^{-1}$, which is much higher than that of the RGO-CMK-5 electrode $\left(144.4 \mathrm{~F} \mathrm{~g}^{-1}\right.$ at $\left.0.2 \mathrm{~A} \mathrm{~g}^{-1}\right),{ }^{56}$ the curved graphene electrode $\left(154.1 \mathrm{~F} \mathrm{~g}^{-1}\right.$ at $\left.1 \mathrm{~A} \mathrm{~g}^{-1}\right),{ }^{57}$ and the $3 \mathrm{DG}-\mathrm{MnO}_{2}-13 \%$ electrode $\left(36 \mathrm{~F} \mathrm{~g}^{-1}\right.$ at $\left.0.5 \mathrm{~A} \mathrm{~g}^{-1}\right)^{58}$ in a two-electrode system. Notably, the capacitance was $242 \mathrm{~F} \mathrm{~g}^{-1}$ at a high current density of $50 \mathrm{~A} \mathrm{~g}^{-1}$. Fig. 8c reveals that the capacitance decreases quickly from 319 to $295 \mathrm{~F}$ $\mathrm{g}^{-1}$ when the current density increases from 0.25 to $1 \mathrm{~A} \mathrm{~g}^{-1}$. And then, it drops slowly at higher current densities ranging from 1$50 \mathrm{~A} \mathrm{~g}^{-1}$. Fig. 8d represents the Ragone plot, which shows that the energy density exhibits only a minimal drop with the increase in power density. As is already known, the energy density of devices is decided by capacitance $(C)$ and voltage $(V)$. In aqueous electrolytes, the maximum voltage is $1 \mathrm{~V}$ due to the oxygen-evolution reaction. In the present study, the energy and power density were $8.4 \mathrm{~W} \mathrm{~h} \mathrm{~kg}^{-1}$ and $6.9 \mathrm{~kW} \mathrm{~kg}^{-1}$ at a current density of $50 \mathrm{~A} \mathrm{~g}^{-1}$, respectively, which confirmed an outstanding power performance. These values are higher than previously reported carbon materials ${ }^{59-61}$ studied under the same measurement conditions.

Cycling stability is one of the most important parameters for supercapacitors. The cycling stability of the HPC-2-based supercapacitor was investigated by a consecutive chargedischarge measurement at a constant current density of $2 \mathrm{~A} \mathrm{~g}^{-1}$ for 10000 cycles. The specific capacitance of the HPC-2 
electrode gradually decreased with increasing cycles (Fig. 9a) and a capacitance retention of $93.9 \%$ was obtained after 10000 cycles, indicating good electrochemical stability. The rectangular CV profile (Fig. 9a, inset) and Nyquist plots (Fig. 9b) with negligible changes after 10000 cycles also supported electrochemical cyclability. Again, the small semicircle in the highfrequency region and the almost vertical line in the lowfrequency region indicated that HPC-2 based super capacitors had an excellent electrical conductivity.

\section{Conclusions}

CCPs were prepared by simple Friedel-Crafts acylation and subsequent Baeyer-Villiger oxidation of CPs. Presence of $\mathrm{COOH}$ groups in CCP was confirmed by elemental analysis, IR spectroscopy, TGA and TPD methods. HPCs were prepared by $\mathrm{KOH}$ activation of CCPs and subsequent carbonization. HPCs were thoroughly characterized by nitrogen adsorption-desorption method, X-ray diffraction (XRD) and Raman spectroscopy. The $S_{\mathrm{BET}}$ and $V_{\text {total }}$ of the HPCs increased with $\mathrm{KOH}$ to CCP ratio of 1-3. HPC-2 prepared with mass ratio of $\mathrm{KOH}$ to CCP two gave a specific surface area of $2098.2 \mathrm{~m}^{2} \mathrm{~g}^{-1}$ and a porosity volume of $1.28 \mathrm{~cm}^{3} \mathrm{~g}^{-1}$. A symmetrical EDLC using the HPC-2 as the electrode showed superior capacitive behavior when compared with HPC-1 and HPC-3. EDLC from HPC-2 possess specific capacitance of $286 \mathrm{~F} \mathrm{~g}^{-1}$ at a current density of $2 \mathrm{~A} \mathrm{~g}^{-1}$ and had capacitance-retention ratio of $93.9 \%$ after 10000 cycles. Thus, HPCs derived from CCPs exhibit great potential for applications in energy storage.

\section{Conflicts of interest}

There are no conflicts to declare.

\section{References}

1 Y. Wang, B. Chang, D. Guan and X. Dong, J. Solid State Electrochem., 2015, 19, 1783-1791.

2 J. Wong, Y. Chen, K. Cao, L. Yang, H. John and X. Tao, ACS Appl. Mater. Interfaces, 2018, 10(46), 39839-39850.

3 Y. Zhang, X. Liu, S. Wang, S. Dou and L. Li, J. Mater. Chem., 2016, 4, 10869-10877.

4 H. Hwang, C. H. Kima, J. Wee, J. H. Han and C. Yang, Appl. Surf. Sci., 2019, 489, 708-716.

5 X. Xiao, Y. Zeng, H. Feng, K. Xu, G. Zhong, S. Wu, C. Wang, W. Zhao, W. Su, Z. Wei and X. Lu, ChemNanoMat, 2019, 5, 152-157.

6 B. Fang, J. H. Kim, M.-S. Kim, A. Bonakdarpour, A. Lam, D. P. Wilkinson and J.-S. Yu, J. Mater. Chem., 2012, 22, 19031-19038.

7 R. B. Rakhi, B. Ahmed, D. Anjum and H. N. Alshareef, ACS Appl. Mater. Interfaces, 2016, 8, 18806-18814.

8 W. Ma, S. Chen, S. Yang, W. Chen, W. Weng, Y. Cheng and M. Zhu, Carbon, 2017, 113, 151-158.

9 X. Chen, S. Gao, H. Mi, C. Jia, Z. Li, L. Sun and X. Zhang, Appl. Surf. Sci., 2019, 486, 490-498.
10 M. Li, Y. Zhang, L. Yang, Y. Liu and J. Yao, Electrochim. Acta, 2015, 166, 310-319.

11 H. Duan, T. Yan, Z. Li, G. Chen, J. Zhang, L. Shi and D. Zhang, Sustainable Energy Fuels, 2017, 1, 1557-1567.

12 W. Geng, F. Ma, G. Wu, S. Song, J. Wan and D. Ma, Electrochim. Acta, 2016, 191, 854-863.

13 V. Sattayarut, T. Wanchaem, P. Ukkakimapan, V. Yordsri, P. Dulyaseree, M. Phonyiem, M. Obata, M. Fujishige, K. Takeuchi, W. Wongwiriyapan and M. Endo, RSC Adv., 2019, 9, 21724-21732.

14 X. Song, X. Ma, Y. Li, L. Ding and R. Jiang, Appl. Surf. Sci., 2019, 487, 189-197.

15 X. Yang, X. Zhuang, Y. Huang, J. Jiang, H. Tian, D. Wu, F. Zhang, Y. Mai and X. Feng, Polym. Chem., 2015, 6, 10881095.

16 Z. Lin, H. Tian, F. Xu, X. Yang, Y. Mai and X. Feng, Polym. Chem., 2016, 7, 2092-2098.

17 H. Tian, Z. Lin, F. Xu, J. Zheng, X. Zhuang, Y. Mai and X. Feng, Small, 2016, 12, 3155-3163.

18 Z. Lin, H. Tian, F. Xu, X. Yang, Y. Mai and X. Feng, Polym. Chem., 2016, 7, 2092-2100.

19 F. Ma, S. Ding, H. Ren and P. Peng, RSC Adv., 2019, 9, 1833318343.

20 W. Geng, F. Ma, G. Wu, S. Song, J. Wan and D. Ma, Electrochim. Acta, 2016, 191, 854-863.

21 T. Liu, L. Zhang, B. Cheng and J. Yu, Adv. Energy Mater., 2019, 9, 1803900.

22 M. Oschatz, L. Borchardt, K. Pinkert, S. Thieme, M. R. Lohe, C. Hoffmann, M. Benusch, F. M. Wisser, C. Ziegler, L. Giebeler, M. H. Rümmeli, J. Eckert, A. Eychmüller and S. Kaskel, Adv. Energy Mater., 2014, 4, 130645-130654.

23 Y. He, X. Zhuang, C. Lei, L. Lei, Y. Hou, Y. Mai and X. Feng, Nano Today, 2019, 24, 103-119.

24 Y. Guo, Z. Shi, M. Chen and C. Wang, J. Power Sources, 2014, 252, 235-243.

25 S. Song, F. Ma, G. Wu, D. Ma, W. Geng and J. Wan, J. Mater. Chem. A, 2015, 3, 18154-18162.

26 J. Deng, T. Xiong, F. Xu, M. Li, C. Han, Y. Gong, H. Wang and Y. Wang, Green Chem., 2015, 17, 4053-4060.

27 Y. S. Wang, C. Y. Wang and M. M. Chen, New Carbon Mater., 2009, 24, 187-190.

28 J. Yang, K. Nakabayashi, J. Miyawaki and S. H. Yoon, Carbon, 2016, 106, 28-36.

29 B. Qin, Q. Wang, X. Zhang, X. Xie, L. Jin and Q. Cao, Electrochim. Acta, 2018, 283, 655-663.

30 D. Li, M. B. Müller, S. Gilje, R. B. Kaner and G. G. Wallace, Nat. Nanotechnol., 2008, 3, 101-105.

31 S. Niyogi, E. Bekyarova, M. E. Itkis, J. L. McWilliams, M. A. Hamon and R. C. Haddon, J. Am. Chem. Soc., 2006, 128, 7720-7721.

32 G. Eda, G. Fanchini and M. Chhowallal, Nat. Nanotechnol., 2008, 3, 270-274.

33 B. William, S. Hummers and R. E. Offeman, J. Am. Chem. Soc., 1957, 80, 1339.

34 S. Park and R. S. Ruoff, Nat. Nanotechnol., 2009, 4, 217-224.

35 S. Song, F. Ma, G. Wu, D. Ma, W. Geng and J. Wan, J. Mater. Chem. A, 2015, 3, 18154-18162. 
36 W. Yang, W. Yang, F. Ding, L. Sang, Z. Ma and G. Shao, Carbon, 2017, 111, 419-427.

37 J. A. Monge, D. C. Amoros, A. Gungor and L. Toppare, Fuel, 2001, 80, 41-48.

38 B. K. Pradhan and N. K. Sandle, Carbon, 1999, 37, 1323-1332.

39 H. M. Zhu, J. H. Yan, X. G. Jiang, Y. E. Lai and K. F. Cen, J. Hazard. Mater., 2008, 153, 670-676.

40 G. X. Zhao, L. Jiang, Y. D. He, J. X. Li, H. L. Dong, X. K. Wang and W. P. Hu, Adv. Mater., 2011, 23, 3959-3963.

41 T. Metzinger and K. J. Hüttinger, Carbon, 1997, 35, 885-892.

42 T. P. Eskay, P. F. Britt and A. C. Buchanan, Energy Fuels, 1996, 10, 1257-1261.

43 T. Metzinger, Untersuchungen zur Vernetzung der Bindepechmatrix van ohlenstoffkdrpern mit Molekularem Sauerstofl, PhD thesis, Universitgt Karlsruhe, Germany, 1996.

44 C. Tangsathitkulchai, Y. Ngernyen and M. Tangsathitkulchai, Korean J. Chem. Eng., 2006, 23, 1046-1054.

45 S. Yu, H. Wang, C. Hu, Q. Zhu, N. Qiao and B. Xu, J. Mater. Chem. A, 2016, 4, 16341-16348.

46 T. Ouyang, K. Cheng, F. Yang, L. Zhou, K. Zhu, K. Ye, G. Wang and D. Cao, J. Mater. Chem. A, 2017, 5, 14551-14561.

47 J. Luo, W. Zhong, Y. Zou, C. Xiong and W. Yang, ACS Appl. Mater. Interfaces, 2017, 9, 317-326.

48 D. Shan, J. Yang, W. Liu, J. Yan and Z. Fan, J. Mater. Chem. A, 2016, 4, 13589-13602.
49 H. Preiss, G. Oliew and K. Szulzewsky, Fuel, 1994, 73, 243249.

50 E. Raymundo-Piñero, K. Kierzek, J. Machnikowski and F. Béguin, Carbon, 2006, 44, 2498-2507.

51 J. Chmiola, G. Yushin, Y. Gogotsi, C. Portet, P. Simon and P. L. Taberna, Science, 2006, 313, 1760-1763.

52 N. Choudhary, C. Li, J. Moore, N. Nagaiah, L. Zhai, Y. Jung and J. Thomas, Adv. Mater., 2017, 29, 1-30.

53 X. Fan, C. Yu, J. Yang, Z. Ling, C. Hu, M. Zhang and J. Qiu, Adv. Energy Mater., 2015, 5, 1-7.

54 M.-S. Park, S. Cho, E. Jeong and Y.-S. Lee, J. Ind. Eng. Chem., 2015, 23, 27-32.

55 Y. Guo, Z. Shi, M. Chen and C. Wang, J. Power Sources, 2014, 252, 235-243.

56 Z. Lei, Z. Liu, H. Wang, X. Sun, L. Lu and X. Zhao, J. Mater. Chem. A, 2013, 1, 2313-2321.

57 C. Liu, Z. Yu, D. Neff, A. Zhamu and B. Z. Jang, Nano Lett., 2010, 10, 4863-4868.

58 X. Sun, H. Wang, Z. Lei, Z. Liu and L. Wei, RSC Adv., 2014, 4, 20233-20240.

59 B. Lv, P. Li, Y. Liu, S. Lin, B. Gao and B. Lin, Appl. Surf. Sci., 2018, 437, 169-175.

60 X. Hao, J. Wang, B. Ding, Y. Wang, Z. Chang, H. Dou and X. Zhang, J. Power Sources, 2017, 352, 34-41.

61 Y. Chen, G. Zhang, J. Zhang, H. Guo, X. Feng and Y. Chen, J. Mater. Sci. Technol., 2018, 34, 2189-2196. 